\title{
Antioxidant Enzyme Activities and Gene Expression Patterns in Leaves of Kentucky Bluegrass in Response to Drought and Post-drought Recovery
}

\author{
Lixin Xu \\ Department of Forestry, Turfgrass Institute, Beijing Forestry University, 100083, Beijing, \\ China; and the Department of Plant Biology and Pathology, Rutgers University, 59 Dudley \\ Road, New Brunswick, NJ 08901 \\ Liebao Han \\ Department of Forestry, Turfgrass Institute, Beijing Forestry University, 100083, Beijing, \\ China \\ Bingru Huang ${ }^{1}$ \\ Department of Plant Biology and Pathology, Rutgers University, 59 Dudley Road, New \\ Brunswick, NJ 08901
}

\begin{abstract}
Additional InDEX WORDs. dehydration tolerance, oxidative stress, transcript, water stress
Abstract. The objectives of this study were to examine antioxidant enzyme responses to drought stress and rewatering at both enzymatic activity and transcript levels and to determine the major antioxidant processes associated with drought tolerance and post-drought recovery for a perennial grass species, kentucky bluegrass (Poa pratensis). Antioxidant enzyme responses to drought and rewatering in a drought-tolerant cultivar (Midnight) and a drought-sensitive cultivar (Brilliant) were compared in a growth chamber. Plants were exposed to 22 days of drought stress for 'Midnight' and 18 days for 'Brilliant' before rewatering to allow the leaf relative water content (RWC) of both cultivars to drop to the same level. 'Midnight' exhibited higher photochemical efficiency $\left(F_{\mathrm{v}} / \mathrm{F}_{\mathrm{m}}\right)$ and lower electrolyte leakage compared with 'Brilliant' when at the same water deficit status (26\% to $28 \%$ RWC). After 6 days of rewatering, all physiological parameters returned to the control level for 'Midnight', but only $F_{v} / F_{m}$ fully recovered for 'Brilliant'. The transcript level of cytosolic copper/zinc superoxide dismutase (cyt Cu/Zn SOD) and ascorbate peroxidase (APX) was significantly higher in 'Midnight' than in 'Brilliant' when exposed to the same level of water deficit (26\% to $28 \%$ RWC), suggesting that SOD and APX could be involved in scavenging oxidative stressinduced reactive oxygen species in kentucky bluegrass through changes in the level of gene expression. Significantly higher activities of APX, monodehydroascorbate reductase, glutathione reductase, and dehydroascorbate reductase as well as lower lipid peroxidation levels were observed in 'Midnight' versus 'Brilliant' when exposed to drought. However, the activities of SOD, catalase (CAT), and guaiacol peroxidase (POD) did not differ between the two cultivars. After 6 days of rewatering, 'Midnight' displayed significantly higher activity levels of CAT, POD, and APX compared with 'Brilliant'. The enzyme activity results indicate that enzymes involved in the ascorbate-glutathine cycle may play important roles in antioxidant protection to drought damage, whereas CAT, POD, and APX could be associated with better post-drought recovery in kentucky bluegrass.
\end{abstract}

Drought stress is one of the most detrimental abiotic stresses for plant growth and function in water-limiting environments. Drought tolerance has been associated with alteration of antioxidant metabolisms in various plant species, including perennial grass species (DaCosta and Huang, 2007; Fu and Huang, 2001; Jiang and Huang, 2001). Drought induces oxidative stress resulting from increased production of reactive oxygen species (ROS), including superoxide $\left(\mathrm{O}_{2}{ }^{*}-\right)$, singlet oxygen $\left({ }^{1} \mathrm{O}_{2}\right)$, hydroxyl radical $\left(\mathrm{OH}^{*}\right)$, and hydrogen peroxide $\left(\mathrm{H}_{2} \mathrm{O}_{2}\right)$, which can attack lipids, proteins, carbohydrates, and nucleic acids (Smirnoff, 1993). To minimize and eliminate oxidative damage,

Received for publication 4 Apr. 2011. Accepted for publication 13 June 2011. We thank both the Chinese Scholarship Council and Rutgers Center for Turfgrass Science for funding support of this research. Thanks also go to Dr. Qi Chai for help with the preparation of plant materials and Emily Merewitz, David Jespersen, Dr. Chenping Xu, and Patrick Burgess for critical review of the manuscript

${ }^{1}$ Corresponding author. E-mail: huang@aesop.rutgers.edu. plants have evolved an antioxidant defense system comprising enzymes such as superoxide dismutase, catalase, peroxidases, monodehydroascorbate reductase (MR), glutathione reductase (GR), dehydroascorbate reductase (DR), and other nonenzymatic constituents such as $\alpha$-tocopherol, ascorbate, and reduced glutathione; the antioxidants remove, neutralize, and scavenge the ROS at different cellular locations (Asada, 1999; Mittler, 2002; Shah et al., 2001).

Superoxide dismutase is the first line of defense against oxidative stress in plants and is responsible for scavenging superoxide to produce hydrogen peroxide, reducing the risk of highly reactive hydroxyl radical formation from superoxide through the metal-catalyzed Haber-Weiss-type reaction (Smirnoff, 1993). SOD is categorized into three groups on the basis of the metal cofactor, namely Mn-SOD, Cu/Zn-SOD, and Fe-SOD. Mn-SOD is predominantly found in mitochondria and peroxisomes (Alscher et al., 2002); Cu/Zn-SODs are mainly located in the cytosol and chloroplasts; Fe-SOD is predominantly detected in chloroplasts (Gomez et al., 1999) and has 
also been reported in cytosolic, mitochondrial, and peroxisomal fractions (Arora et al., 2002). Catalase, peroxidases, and the ascorbate-glutathione cycle (AsA-GSH cycle), which involves four enzymes including ascorbate peroxidase, GR, MR, and $\mathrm{DR}$, are the major components scavenging $\mathrm{H}_{2} \mathrm{O}_{2}$, the product of dismutation of $\mathrm{O}_{2} *$ - by SOD at different cellular compartments (Asada, 1999). CAT enzymes are mostly localized in peroxisomes (Fridovich, 1978; Mhamdi et al., 2010) with the exception of CAT-3 from maize (Zea mays), which is mitochondrial (Scandalios et al., 1980). Many isoenzymes of guaiacol peroxidase, which may tend to ameliorate $\mathrm{H}_{2} \mathrm{O}_{2}$ accumulation in plant tissues, are localized in vacuoles, the cell wall, and the cytosol but not in organelles (Asada, 1992). Compared with POD, APX isoenzymes are distributed in at least four distinct cellular compartments: stromal APX and thylakoid membranebound APX in chloroplasts, microbody membrane-bound APX, and cytosolic APX (Shigeoka et al., 2002; Yoshimura et al., 2001).

Previous studies have indicated that higher activity levels of antioxidant enzymes may contribute to better drought tolerance by increasing the protection capacity against oxidative damage (Sharma and Dubey, 2005; Turkan et al., 2005). However, alterations in antioxidant enzyme activities under drought stress are dependent on plant species, cultivar, and stress intensity and duration (DaCosta and Huang, 2007; Rensburg and Kruger, 1994; Zhang and Kirkham, 1996). In leaves of three bentgrass (Agrostis spp.) species exposed to prolonged drought stress, both SOD and CAT activities decreased along with increased lipid peroxidation (DaCosta and Huang, 2007). In leaves of kentucky bluegrass and tall fescue (Festuca arundinacea) both exposed to prolonged surface soil drying, SOD activity increased, whereas CAT and POD activities remained unchanged, and SOD, POD, and CAT decreased with increasing stress duration under full soil drying (Fu and Huang, 2001). Zhang and Schmidt (1999) found that drought stress had no effect on leaf SOD activity in kentucky bluegrass.

Previous studies, as mentioned previously, revealed the variable responses of antioxidant enzymes to different durations and severities of drought stress in different plant species, but how antioxidant enzymes differ when plants of varied drought tolerance exposed to the same level of water deficit and how they are related to post-drought recovery are not well understood. Such information is critical to further describe antioxidant metabolism associated with drought tolerance and post-drought recovery when water once again becomes available. Furthermore, limited research has focused on the gene expression patterns in conjunction with the underlying enzymes promoting drought tolerance and post-drought recovery. Understanding the association of antioxidant enzyme activity and gene expression with genetic variation in drought tolerance is important for further understanding molecular factors controlling antioxidant defense for drought tolerance. The present study was designed to examine antioxidant enzyme responses to drought stress and rewatering at both enzymatic activity and transcript levels as well as to determine the predominant antioxidant processes associated with drought survival and post-drought recovery in a perennial grass species, kentucky bluegrass, widely used as forage and turfgrass. These objectives were addressed by comparing physiological responses and changes in antioxidant enzyme activities and gene expression patterns in response to drought stress and rewatering between 'Midnight' and 'Brilliant' when exposed to the same level of water deficit. Previous physiological analyses demonstrated that 'Midnight' had superior drought tolerance to 'Brilliant' (Hu et al., 2010; Merewitz et al., 2010; Xu et al., 2011).

\section{Materials and Methods}

Plant materials AND Growing conditions. Sods of two commonly used kentucky bluegrass cultivars, drought-tolerant 'Midnight' and drought-sensitive 'Brilliant', were collected from a 3-year-old field plots on Horticultural Farm II at Rutgers University, New Brunswick, NJ. The underlying soil is Nixon loam (fine-loamy, mixed, semiactive mesic typic Hapludults) with a $\mathrm{pH}$ of 6.3 and organic matter content of $3.0 \%$. The root zone of sods was removed to allow crowns to regenerate new roots systems once planted in plastic pots $(13 \mathrm{~cm}$ diameter and 60 $\mathrm{cm}$ deep) filled with a mixture of sand and soil $(1: 1 \mathrm{v} / \mathrm{v})$. Plants were established for $60 \mathrm{~d}$ in a greenhouse maintained at average day/night temperatures of $23 / 16{ }^{\circ} \mathrm{C}$ and an average $11-\mathrm{h}$ photoperiod at $860 \mu \mathrm{mol} \cdot \mathrm{m}^{-2} \cdot \mathrm{s}^{-1}$ photosynthetically active radiation $(P A R)$. During establishment, plants were trimmed weekly to $\approx 10 \mathrm{~cm}$, watered every $2 \mathrm{~d}$, and fertilized every week with half-strength Hoagland's solution (Hoagland and Arnon, 1950). Two weeks before the imposition of drought, all pots were transferred to a growth chamber for acclimation. The growth chamber were set to $20 / 15{ }^{\circ} \mathrm{C}$ (day/night), $70 \%$ relative humidity, $600 \mu \mathrm{mol} \cdot \mathrm{m}^{-2} \cdot \mathrm{s}^{-1} P A R$, and a $12-\mathrm{h}$ photoperiod.

Treatments AND EXPERIMENTAL Design. After 2-week acclimation to growth chamber conditions, plants were then exposed to three treatments: 1) well-watered control treatment: plants were watered every $2 \mathrm{~d}$ to maintain soil volumetric water content (SWC) at $25 \% ; 2$ ) drought-stress treatment: irrigation was withheld for $18 \mathrm{~d}$ in 'Brilliant' and $22 \mathrm{~d}$ in 'Midnight' with SWC dropping to $6 \%$ for both cultivars (this allowed leaf internal water deficit to reach the same level for both cultivars); and 3) rewatering treatment: after drought, plants were rewatered daily for a total of $6 \mathrm{~d}$ to maintain SWC at $26 \%$. SWC was measured as an indication of the level of soil water deficit. The SWC in a 0 - to 20 -cm-deep soil layer of each pot was measured using time domain reflectometry (Soil Moisture Equipment, Santa Barbara, CA) by inserting the 20 -cm-long wave guide probe vertically in the top 20 -cm soil profile.

Each treatment for each species had four replicates (four pots) and was arranged in a completely randomized design with two differing factors (watering treatments and grass cultivars).

Physiological analysis. Physiological changes of the two cultivars in response to drought stress and rewatering were evaluated by measuring turf quality (TQ), leaf relative water content, $\mathrm{F}_{\mathrm{v}} / \mathrm{F}_{\mathrm{m}}$, and cellular membrane stability expressed as electrolyte leakage (EL). Measurements were taken at various time points after the initiation of drought stress and rewatering.

Turf quality is a subjective assessment to determine the overall turf performance. It is determined based on a combination of factors, including foliage color, stand uniformity, and overall density of the upper canopy. TQ is rated on a scale from 1 to 9 , in which 1 is completely desiccated and brown turf, 6 is the minimal acceptable level, and 9 is for a fully turgid and green turf canopy (Turgeon, 2008).

For EL, fresh leaves $(0.1 \mathrm{~g})$ were collected, rinsed with deionized water, and immersed in $20 \mathrm{~mL}$ deionized water. The conductivity of the solution $\left(\mathrm{C}_{\text {initial }}\right)$ was measured using a conductivity meter (YSI, Yellow Springs, OH) after the leaves were incubated in deionized water for $24 \mathrm{~h}$ on a shaker. 
Leaves were then killed by autoclaving them at $140{ }^{\circ} \mathrm{C}$ for 20 min. The conductivity of killed tissues $\left(\mathrm{C}_{\max }\right)$ was measured after samples were cooled down to room temperature. EL was calculated as the percentage of $\mathrm{C}_{\text {initial }}$ over $\mathrm{C}_{\max }$ (Blum and Ebercon, 1981).

Leaf RWC was determined from fresh weight (FW) $(\approx 0.15 \mathrm{~g})$, dry weight (DW), and turgid weight (TW) using the formula RWC $(\%)=[(\mathrm{FW}-\mathrm{DW}) /(\mathrm{TW}-\mathrm{DW})] \times 100$. Leaves were collected from plants and immediately weighed for determination of FW. Samples were then immersed in deionized water and kept in the dark for $12 \mathrm{~h}$ at $4{ }^{\circ} \mathrm{C}$. After this, leaves were removed from deionized water, gently blotted dry, and weighed for TW. Samples were then dried in an oven set to $80^{\circ} \mathrm{C}$ for at least $72 \mathrm{~h}$ and weighed for DW (Barrs and Weatherley, 1962).

Leaf photochemical efficiency was estimated by measuring chlorophyll fluorescence using a fluorescence induction monitor (BioScientific, Hoddesdon, UK). The $\mathrm{F}_{\mathrm{v}} / \mathrm{F}_{\mathrm{m}}$ ratios were measured on three sets (subsamples) of five individual leaves from each replicate. Leaves were dark-adapted for $30 \mathrm{~min}$ before measurement using a leaf chamber attached to the fluorescence induction.

ANTIOXIDANT ENZYMe ACTIVITY AND LIPID PEROXIDATION MEASUREMENT. Determination of enzyme activity was carried out using the method previously described by Zhang and Kirkham (1996) as well as Bian and Jiang (2009). Briefly, 0.35 g of fresh leaf tissue was ground to a fine powder using a mortar and pestle and extraction was performed with $4 \mathrm{~mL}$ of extraction buffer (50 mм potassium phosphate, $1 \mathrm{~mm}$ ethylenediaminetetraacetic acid, 1\% polyvinylpyrrolidone, $1 \mathrm{~mm}$ dithiothreitol, and $1 \mathrm{~mm}$ phenylmethylsulfonyl with $\mathrm{pH}$ of 7.8 ). The extractions were centrifuged at $15,000 \mathrm{~g}_{\mathrm{n}}$ for $30 \mathrm{~min}$ at $4{ }^{\circ} \mathrm{C}$, and supernatant was collected for enzyme assay and malondialdehyde (MDA) content measurement. The SOD (EC 1.15.1.1) activity was measured by recording the rate of p-nitro blue tetrazolium chloride reduction in absorbance at $560 \mathrm{~nm}$ (Giannopolities and Rise, 1977). The activity of CAT (EC 1.11.7.6), POD (EC 1.11.1.7), APX (EC 1.11.1.1), MR (EC 1.6.5.4), DR (EC 1.8.5.1), and GR (EC 1.6.4.2) was determined by following the changes in absorbance at 240, 470, 290, 340, 265, and $340 \mathrm{~nm}$, respectively. Protein content was determined using Bradford's (1976) method.

The lipid peroxidation was measured in terms of MDA content (Dhindsa and Matowe, 1981) with some modifications. A $0.8-\mathrm{mL}$ aliquot of supernatant was mixed with $1.6 \mathrm{~mL}$ of $20 \%$ trichloroacetic acid containing $0.5 \%$ thiobarbituric acid. The mixture was heated at $95^{\circ} \mathrm{C}$ for $30 \mathrm{~min}$, quickly cooled on ice, and then centrifuged at $10,000 \mathrm{~g}$ for $10 \mathrm{~min}$. The absorbance of the supernatant was read at 532 and $600 \mathrm{~nm}$. The concentration of MDA was calculated using an extinction coefficient of 155 $\mathrm{mm}^{-1} \mathrm{~cm}^{-1}$ (Health and Packer, 1968).

GeNE EXPRESSION ANALYSIS. Gene expression was performed using a reverse transcriptase polymerase chain reaction (RTPCR). Total RNA from the grass leaves was isolated using Plant RNeasy Mini kit (Qiagen, Chatsworth, CA) and was treated with DNase (Turbo DNA-Free Kit; Ambion, Austin, TX) to remove contaminating genomic DNA. RNA was reversetranscribed with the Ready to go RT- PCR beads (GE Health Care/Amersham Pharmacia Biotech, Piscataway, NJ). The synthesized cDNA was subjected to PCR for 35 cycles using primers for CAT, POD, cytosolic $\mathrm{Cu} / \mathrm{ZnSOD}$, chloroplastic $\mathrm{Cu} /$ ZnSOD, MnSOD, FeSOD, cytosolic APX, GR, DHAR, MR, and 18S (as internal control) for PCR obtained from Bian and Jiang (2009). Aliquots of individual PCR products were re- solved through agarose gel electrophoresis and images were captured by Quantity One (Bio-Rad Laboratories, Hercules, CA) and the bands were also determined with the Discovery Series Quantity One (Version 4.6.2; Bio-Rad Laboratories).

Statistical analysis. Effects of watering treatment, grass cultivars, and corresponding interactions were determined by analysis of variance according to the general linear model procedure of SAS (Version 9.0; SAS Institute, Cary, NC). Differences between means were separated by Fisher's protected least significance difference test at the $0.05 P$ level.

\section{Results and Discussion}

Physiological analysis of Drought tolerance AND POSTDROUGHT RECOVERY. TQ declined in both cultivars during drought stress but at a lower rate in 'Midnight'. This was seen as TQ decreased to the same rating of 5.0 after $18 \mathrm{~d}$ of drought treatment for 'Brilliant' and not until $22 \mathrm{~d}$ for 'Midnight' (Fig. 1). In addition, at 10,15 , and $18 \mathrm{~d}$, 'Midnight' had significantly higher TQ ratings than 'Brilliant'. On rewatering, TQ of 'Midnight' recovered at a faster rate compared with 'Brilliant' although both cultivars had declined to the same level (5.0) by the end of drought treatment.

Cultivar differences in TQ in response to drought or rewatering were confirmed by other physiological changes. Physiological changes in parameters reflect leaf hydration status and physiological status for 'Midnight' and 'Brilliant' during drought stress and rewatering. Leaf RWC of both cultivars declined during the drought period, reaching the same final level (statistically insignificant) after $18 \mathrm{~d}$ for 'Brilliant' (26\%) and 22 d for 'Midnight' (28\%) (Fig. 2A). 'Midnight' was able to maintain higher RWC level than 'Brilliant' under the same duration of drought treatment and fully recovered to the wellwatered control level on $2 \mathrm{~d}$ of rewatering, but RWC in 'Brilliant' only recovered to $83 \%$ of the well-watered control level at $2 \mathrm{~d}$ rewatering and remained unchanged with longer rewatering treatment.

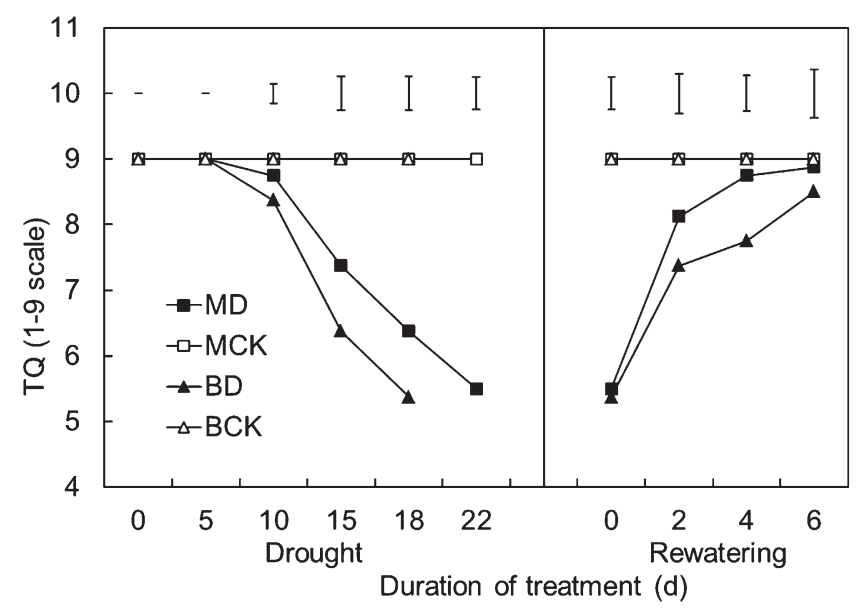

Fig. 1. Turf quality (TQ) changes in two kentucky bluegrass cultivars, droughttolerant 'Midnight' $(\mathrm{MD}=$ 'Midnight' drought stress; $\mathrm{MCK}=$ 'Midnight' control) and drought-sensitive 'Brilliant' ( $\mathrm{BD}=$ 'Brilliant' drought stress; $\mathrm{BCK}=$ 'Brilliant' control) during drought stress and recovery. Vertical bars indicate least significant difference values $(P \leq 0.05)$ for treatment comparison at a given day of treatment $(n=4)$. 

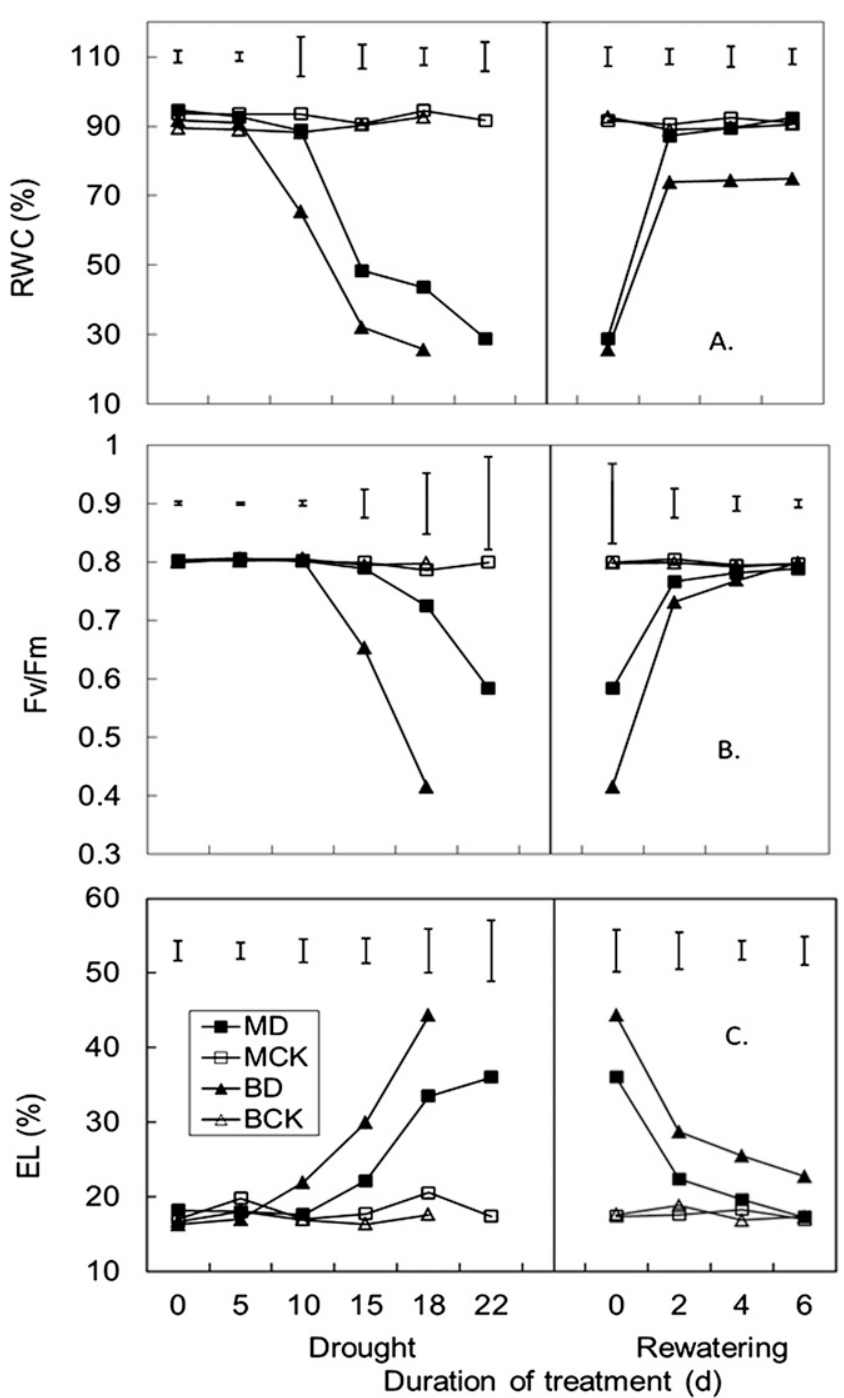

Fig. 2. Changes in leaf relative water content (RWC), photochemical efficiency $\left(\mathrm{F}_{\mathrm{v}} / \mathrm{F}_{\mathrm{m}}\right)$, and electrolyte leakage (EL) of both the stressed and well-watered plants of two kentucky bluegrass cultivars, drought-sensitive 'Brilliant' and drought-tolerant 'Midnight' during drought stress and recovery ( $\mathrm{MD}=$ 'Midnight' drought stress; $\mathrm{MCK}=$ 'Midnight' control; $\mathrm{BD}=$ 'Brilliant' drought stress; $\mathrm{BCK}=$ 'Brilliant' control). Vertical bars indicate least significant difference values $(P \leq 0.05)$ for treatment comparison at a given day of treatment $(n=4)$.

Leaf chlorophyll fluorescence reflects the integrity of photosynthetic apparatus or photochemical efficiency of photosystem II system in the light reaction of photosynthesis (Genty et al., 1987; Kaiser, 1987). Drought decreased the $\mathrm{F}_{\mathrm{v}} / \mathrm{F}_{\mathrm{m}}$ ratio in both cultivars (Fig. 2B). However, $\mathrm{F}_{\mathrm{v}} / \mathrm{F}_{\mathrm{m}}$ remained significantly greater in 'Midnight' than in 'Brilliant' during drought treatment and when compared at the same level of RWC for both cultivars by the end of its cultivar's respective drought period ( $18 \mathrm{~d}$ for 'Brilliant' and $22 \mathrm{~d}$ for 'Midnight'). This indicates that 'Midnight' was able to maintain higher photochemical efficiency than 'Brilliant' at the same level of water deficit. In response to rewatering, $F_{v} / F_{m}$ increased to the well-watered control level after $2 \mathrm{~d}$ of rewatering in 'Midnight' but not until $4 \mathrm{~d}$ of rewatering in 'Brilliant'. Full recovery of $\mathrm{F}_{\mathrm{v}} /$ $F_{m}$ ratio in both cultivars suggests that the functional forms of photosystem II were fully restored on relief of drought stress although RWC had dropped to $26 \%$ to $28 \%$. Huang and Wang (2005) reported that during drought stress, RWC of $25 \%$ was a critical threshold for 'Midnight' recovery because when leaf RWC declined below this threshold during drought stress, RWC and $\mathrm{F}_{\mathrm{v}} / \mathrm{F}_{\mathrm{m}}$ values could not resume to the pre-stressed level on rewatering. Hu et al. (2010) reported that on rewatering, RWC and $\mathrm{F}_{\mathrm{v}} / \mathrm{F}_{\mathrm{m}}$ of 'Midnight' and 'Brilliant' fully recovered after a decline in leaf RWC to $53 \%$ and $39 \%$, respectively, during drought treatment.

Cell membrane stability plays a critical role in maintaining cell turgor and physiological functions, particularly during plant dehydration, and EL has been widely used to estimate cell membrane stability (Blum and Ebercon, 1981; Rachmilevitch et al., 2006). During drought stress, the levels of EL increased significantly for both cultivars, from $\approx 17 \%$ at the initiation of drought stress to $44 \%$ for 'Brilliant' and to $36 \%$ for 'Midnight' by the end of respective drought periods ( $18 \mathrm{~d}$ for 'Brilliant' and $22 \mathrm{~d}$ for 'Midnight'). Leaf EL was significantly lower in 'Midnight' than in 'Brilliant' when compared at the same day of drought stress and at the same level of RWC ( $18 \mathrm{~d}$ of drought for 'Brilliant' and $22 \mathrm{~d}$ for 'Midnight'). An increase in EL is generally considered an index of membrane damage or deterioration (Simon, 1974). Therefore, the results indicate that 'Midnight' maintained better membrane stability with less membrane interruption compared with 'Brilliant' during prolonged drought and when leaves of both cultivars were dehydrated to the same level of water deficit. EL declined rapidly for both cultivars during rewatering with lower EL in 'Midnight' than in 'Brilliant', which indicated better membrane repair in 'Midnight'.

Previous studies (Hu et al., 2010; Merewitz et al., 2010; Xu et al., 2011) also showed that 'Midnight' exhibited better postdrought recovery when compared with 'Brilliant'. However, in those studies, leaves in the two cultivars were not dehydrated to the same level of internal water deficit for the recovery examination; in those cases, the better physiological recovery in 'Midnight' could be the result of the lesser dehydration of leaves during drought before rewatering. The current study examined the physiological recuperative ability of leaves from drought when cultivars were at the same level of internal leaf water deficit (26\% to $28 \%$ RWC) for both cultivars. Our results demonstrated that less severe cellular damages occurred in 'Midnight', as indicated by higher $\mathrm{F}_{\mathrm{v}} / \mathrm{F}_{\mathrm{m}}$ and lower EL, when internal water deficit of both cultivars reached the same level. This could contribute to better drought survival and recuperative capacity and thus could be an important trait to select for drought-tolerant perennial grasses.

MEMBRANE LIPID PEROXIDATION AND ANTIOXIDANT ENZYME ACTIVITY IN RESPONSE TO DROUGHT AND REWATERING. Cultivar variation in physiological responses to drought and rewatering could be associated with changes in membrane lipid peroxidation and associated antioxidant metabolism. Lipid peroxidation is considered a primary cause of membrane oxidative degradation and MDA content is widely used as an indicator for lipid peroxidation (Scandalios, 1993; Zhang and Kirkham, 1996). In this study, drought stress caused an increase in MDA content for both cultivars (Fig. 3). When compared with 'Midnight', MDA content of 'Brilliant' increased at a faster rate and to a greater degree. When RWC of the two cultivars declined to the same level at the end of the drought period, MDA content in 'Brilliant' was significantly higher than that in 'Midnight'. In response to rewatering, MDA content decreased in both cultivars but did not fully recover to the well-watered 


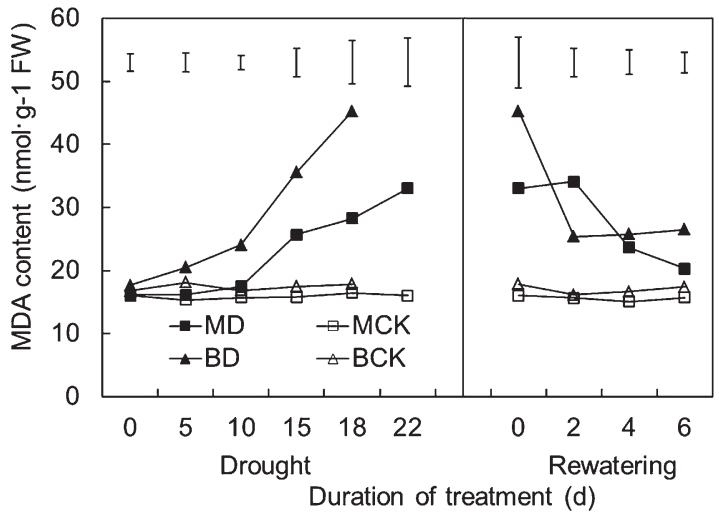

Fig. 3. Changes in lipid peroxidation expressed by malondialdehyde (MDA) content in two kentucky bluegrass cultivars, drought-tolerant 'Midnight' and drought-sensitive 'Brilliant' $(\mathrm{MD}=$ 'Midnight' drought stress; $\mathrm{MCK}=$ 'Midnight' control; $\mathrm{BD}=$ 'Brilliant' drought stress; $\mathrm{BCK}=$ 'Brilliant' control). Vertical bars indicate least significant difference values $(P \leq$ $0.05)$ for treatment comparison at a given day of treatment $(n=4)$.

control level in 'Brilliant', whereas 'Midnight' recovered to the well-watered control level after $6 \mathrm{~d}$ of rewatering. These results indicate that at the same level of internal water deficit, 'Brilliant' exhibited more severe membrane damage as a result of ROSmediated lipid peroxidation as compared with 'Midnight'. With this, it is likely that prolonged periods of drought caused increased levels of lipid peroxidation in both cultivars, which could be associated with the decline in membrane stability (Fig. 2C). Taken together, the increase in both EL and MDA content during prolonged drought indicates that cell membranes were injured in both cultivars but 'Brilliant' was damaged more severely. 'Midnight' suffered from less severe membrane damage and maintained relatively better membrane stability compared with 'Brilliant', which could contribute to better recovery on rewatering.

To minimize the oxidative damage induced by drought as well as other environmental stresses, plants have evolved various enzymatic and non-enzymatic mechanisms to detoxify harmful oxygen species, including enzymes that combat $\mathrm{O}_{2}{ }^{*}$ and $\mathrm{H}_{2} \mathrm{O}_{2}$ such as SOD, CAT, and POD (Smirnoff, 1993). The AsA-GSH cycle involves four enzymes, APX, GR, MR, and DR, and is an alternative and more effective detoxification mechanism against $\mathrm{H}_{2} \mathrm{O}_{2}$ operating both in chloroplasts and the cytosol (Asada, 1992, 1999; Foyer, 1993). APX requires a reductant-ascorbate substrate and has a higher affinity for $\mathrm{H}_{2} \mathrm{O}_{2}$, therefore allowing efficient scavenging of $\mathrm{H}_{2} \mathrm{O}_{2}$ in more specific locations. The regeneration of ascorbate can be catalyzed by either NAD $(\mathrm{P})$ H-dependent MR or GSH-dependent DR coupled with GR (Zhang and Kirkham, 1996). GR also plays a crucial role in protection against oxidative stress by maintaining GSH levels. Working collectively, MR, DR, and GR are involved in the regeneration of antioxidants such as AsA and GSH (Blokhina et al., 2003).

The activity of both SOD (Fig. 4A) and CAT (Fig. 4B) declined under drought stress in both cultivars but did not differ between the two cultivars. Previous reports have also shown that prolonged drought stress decreases the activity of SOD and CAT in kentucky bluegrass and tall fescue (Fu and Huang, 2001). Decreased activity of SOD and CAT indicates that the ability to scavenge for singlet oxygen and $\mathrm{H}_{2} \mathrm{O}_{2}$ in kentucky bluegrass was weakened by drought stress, which may result in free radical-mediated damage, including lipid peroxidation in
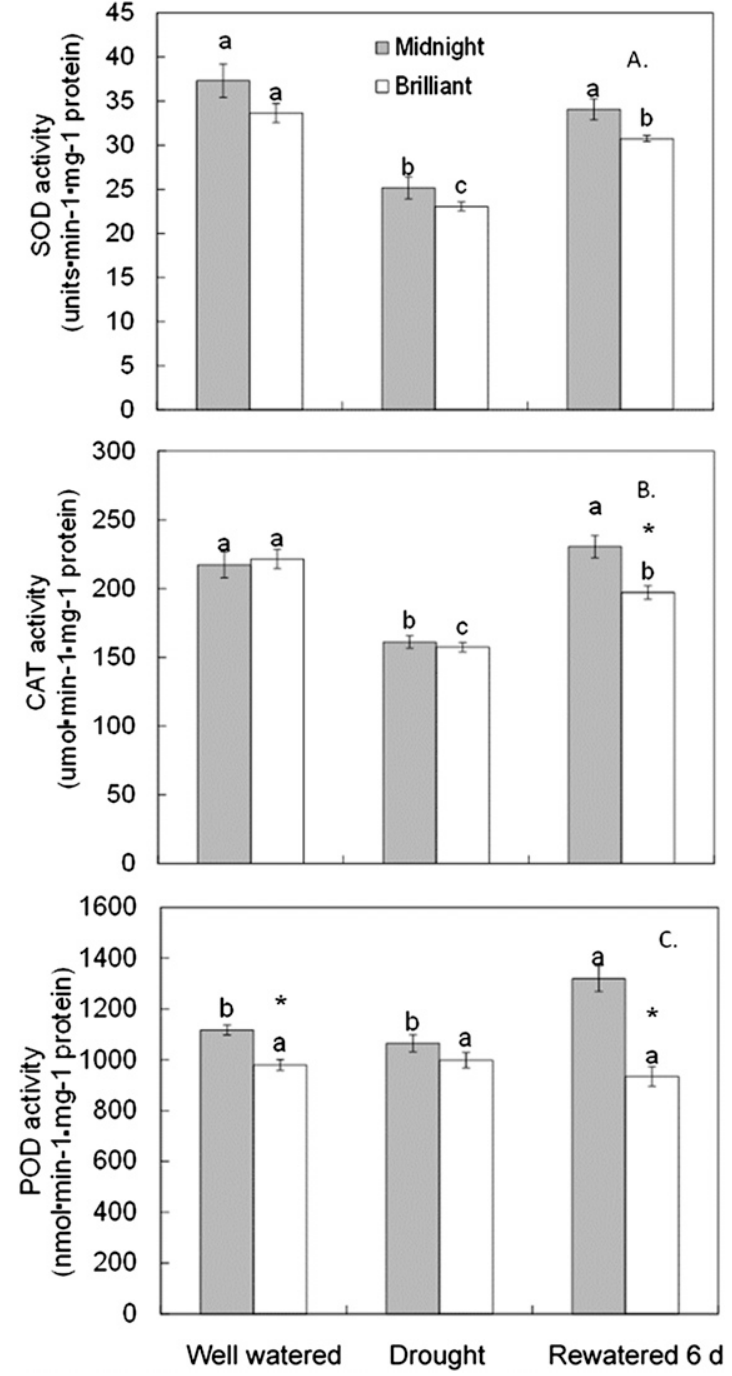

Fig. 4. The activities of superoxide dismutase (SOD), catalase (CAT), and guaiacol peroxidase (POD) under well-watered, drought-stressed ( $22 \mathrm{~d}$ for 'Midnight' and $18 \mathrm{~d}$ for 'Brilliant') and $6 \mathrm{~d}$ rewatering conditions for two kentucky bluegrass cultiavrs, drought-tolerant 'Midnight' and drought-sensitive 'Brilliant'. Bars indicate \pm SE $(n=4)$. For each cultivar, bars having the same letter indicate no significant enzyme activity difference in that particular cultivar. For each treatment, the asterisk means a significant cultivar difference exists $(P \leq 0.05)$.

membranes (Mead, 1976). After 6 d of rewatering, activity levels of SOD and CAT fully recovered to the well-watered control level in 'Midnight' but neither enzyme activity returned to the well-watered activity control level in 'Brilliant'. The activity of POD (Fig. 4C) did not differ for both cultivars between well-watered and drought-stressed plants, which indicated drought had no effect on POD activity in both cultivars. However, compared with well-watered 'Brilliant' plants, wellwatered 'Midnight' plants maintained a higher level of POD activity suggesting higher potential to scavenge $\mathrm{H}_{2} \mathrm{O}_{2}$. Moreover, a significant increase in POD activity for 'Midnight' was observed at $6 \mathrm{~d}$ of rewatering compared with the droughtstressed level and was significantly higher than that in 'Brilliant'. The lack of differences between the cultivars in the activities of SOD, CAT, and POD suggests that these three enzymes may not serve important roles in imparting kentucky bluegrass with tolerance to severe water deficit (26\% to $28 \%$ 
RWC). Sairam et al. (1998) found that SOD activity did not show significant differences among the three contrasting winter wheat (Triticum aestivum) genotypes under both irrigated and water-stressed conditions, whereas APX and CAT were shown to be more important in conferring different drought tolerances. Other reports have shown that SOD activity and chlorophyll content can be used as an indirect selection criterion for screening drought-resistant durum wheat (Triticum durum) (Zaefyzadeh et al., 2009). The discrepancy in the relative changes of different antioxidant enzymes involved in drought responses may be the result of the differences in the level of drought tolerance between plant species and the severity of drought stress used in different studies.

The differential recovery in CAT and POD activities at rewatering implied these two enzymes could contribute to the differing performance of the two cultivars during post-drought recovery. When water enters the cell on rehydration, a more efficient repair mechanism is necessary to restore membrane integrity than during dehydration. In this study, CAT and POD showed significantly higher activities in 'Midnight' relative to 'Brilliant' after $6 \mathrm{~d}$ of rewatering (Fig. 4B-C), possibly providing better $\mathrm{H}_{2} \mathrm{O}_{2}$ protection in different cellular compartments for full hydration and metabolic recovery. To date, there is limited information regarding the response of different antioxidant enzymes to rewatering for two cultivars of a single turfgrass species differing in sensitivity to water deficit, whereas there have been several studies focusing on these aspects in other plant species. Stressed upland rice (Oryza sativa) plants showed higher CAT activity when compared with the control plants during drought treatment and rewatering in WSR I and WSR II (the two cycles of water stress followed by recovery are termed as WSR I, WSR II). An increase in the levels of peroxidase III was also observed in the stressed plants of WSRI, which did not decline after rewatering (Srivalli et al., 2003).

Drought caused a reduction in APX activities (Fig. 5A) but increased both MR (Fig. 5B) and GR (Fig. 5C) activities in both cultivars. The reduction in APX activity coupled to decreased levels of CAT and POD activities during drought stress may have led to increased lipid peroxidation in both cultivars. Significantly higher DR activity was also induced by drought in 'Midnight' but not in 'Brilliant' (Fig. 5D). After $6 \mathrm{~d}$ of rewatering, the activity of APX and MR in 'Midnight' returned to the well-watered control level, whereas 'Brilliant' returned to only $68 \%$ of the well-watered control level in APX activity and remained at a higher MR activity compared with the prestressed level. In both cultivars, at $6 \mathrm{~d}$ rewatering, DR and GR activities remained significantly higher than their respective well-watered control level. Cultivar differences were observed in all of the four enzymes involved in the AsA-GSH cycle at the end of drought treatment. Under drought conditions, 'Midnight' maintained significantly higher activities of APX, MR, DR, and GR than 'Brilliant', which indicated that the lesser lipid peroxidation in 'Midnight' was mainly associated with enzymes in the AsA-GSH cycle for scavenging $\mathrm{H}_{2} \mathrm{O}_{2}$. At $6 \mathrm{~d}$ of recovery, 'Midnight' had significantly higher APX activity but lower DR activity compared with 'Brilliant', which indicates that higher APX activity may contribute to better recuperative capacity in the leaves of 'Midnight' despite lower DR activity. Bian and Jiang (2009) reported that $5 \mathrm{~d}$ of soil drying increased the enzyme activity of APX, MR, and DR in kentucky bluegrass cultivar Midnight and after a single day of rewatering, the activities of these enzymes were significantly higher compared with the controls. In Prunus hybrids, the activity of APX, MR, $\mathrm{DR}$, and GR was downregulated during the rewatering phase
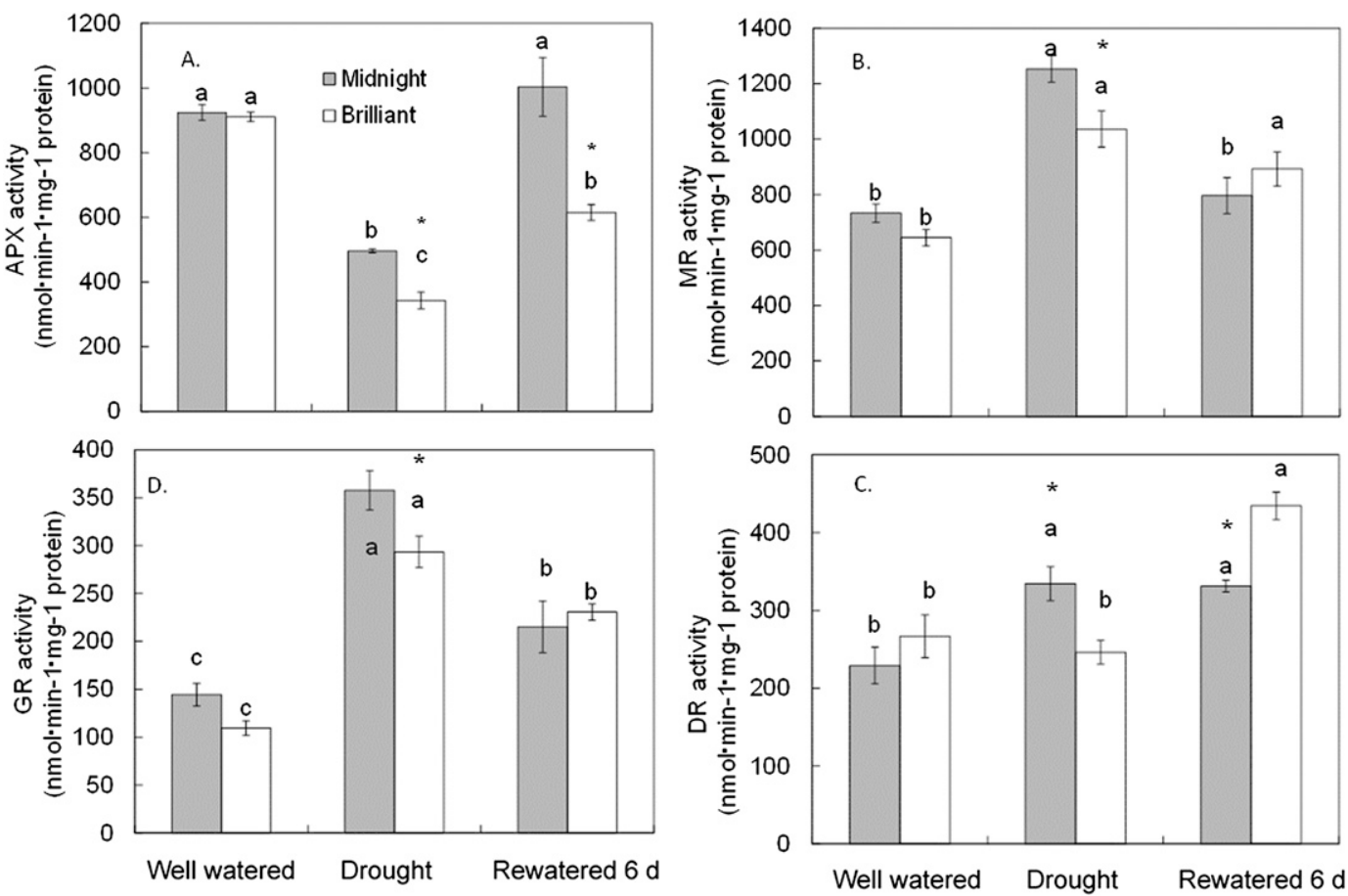

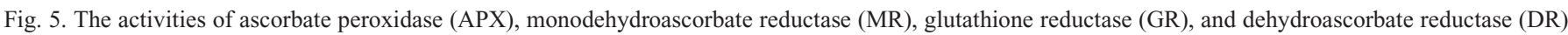
under well-watered, drought-stressed ( $22 \mathrm{~d}$ for 'Midnight' and $18 \mathrm{~d}$ for 'Brilliant') and $6 \mathrm{~d}$ rewatering conditions for two kentucky bluegrass cultivars, droughttolerant 'Midnight' and drought-sensitive 'Brilliant'. Bars indicate \pm SE $(n=4)$. For each cultivar, bars having the same letter indicate no significant enzyme activity difference in that particular cultivar. For each treatment, the asterisk means a significant cultivar difference exists $(P \leq 0.05)$. 
and their values were lower than those found in the droughtstressed plants (Sofo et al., 2005). In wild-type german chamomile (Chamomilla recutita), APX activity was higher in drought-stressed plants than in the well-watered control plants (Baczek-Kwinta et al., 2010).

EXPRESSION OF GENES ENCODING ANTIOXIDANT ENZYMES IN RESPONSE TO DROUGHT AND REWATERING. The involvement of antioxidant defense in promoting drought tolerance of kentucky bluegrass may also be reflected at the gene transcript level. The investigation of gene expression during drought and rewatering underlying the changes in antioxidant enzyme activities could provide insight into molecular adaptation of plants to drought stress. For example, in both resistant and susceptible cowpea (Vigna unguiculata), the leaf cytosolic GR gene was upregulated by drought stress and directly related to the stress intensity (Contour-Ansel et al., 2006). In another study, GR gene expression remained stable under moderate drought stress in tolerant cowpea and an upregulation of $G R$ occurred during recovery from drought, which suggests that moderate drought stress may lead to acclimation to drought stress (TorresFranklin et al., 2008). The transcript abundance of cytosolic $A P X$ and cyt $C u / Z n S O D$ largely increased with increasing drought stress severity, but relatively small increases in APX protein and activity were observed in the leaves of pea (Pisum sativum) (Mittler and Zilinskas, 1994). Drought stress increased transcripts of CAT in horsegram (Macrotyloma uniflorum) seedlings (Reddy et al., 2008) but decreased the transcript abundance of $C A T 1$ and $C A T 2$, whereas $\mathrm{H}_{2} \mathrm{O}_{2}$ content and CAT activity increased in the leaves of wheat (Luna et al., 2005).

In this study, those genes encoding antioxidant enzymes exhibited different expression patterns in response to drought or rewatering and also differed between the two cultivars. Drought stress and rewatering did not alter expression levels of $C A T$, $P O D, F e S O D, M n S O D, G R$, or DR in either cultivar (data not shown), despite the changes in enzyme activity as discussed previously. The expressions of Cyt $\mathrm{Cu} / \mathrm{ZnSOD}$ (Fig. 6A), Chl $C u / Z n S O D$ (Fig. 6B), and Cyt $A P X$ (Fig. 6C) were strongly enhanced by drought stress and then decreased to their respective well-watered control levels after $6 \mathrm{~d}$ of rewatering. Similar observations of enhanced expression of Cyt $A P X$ and Cyt $C u / Z n S O D$ by drought stress were also reported in pea (Mittler and Zilinskas, 1994). The transcript levels of MR (Fig. 6D) were significantly inhibited by drought stress and did not change on rewatering in both cultivars. Cultivar differences were detected in the transcript abundance for Cyt $A P X$ and Cyt $C u / Z n S O D$ under drought conditions; both transcripts levels were significantly higher in 'Midnight' than in 'Brilliant'. Cyt $A P X$ transcript levels were also significantly higher in 'Midnight' than in 'Brilliant' under well-watered conditions and at rewatering. No cultivar differences in the expression levels in Chl
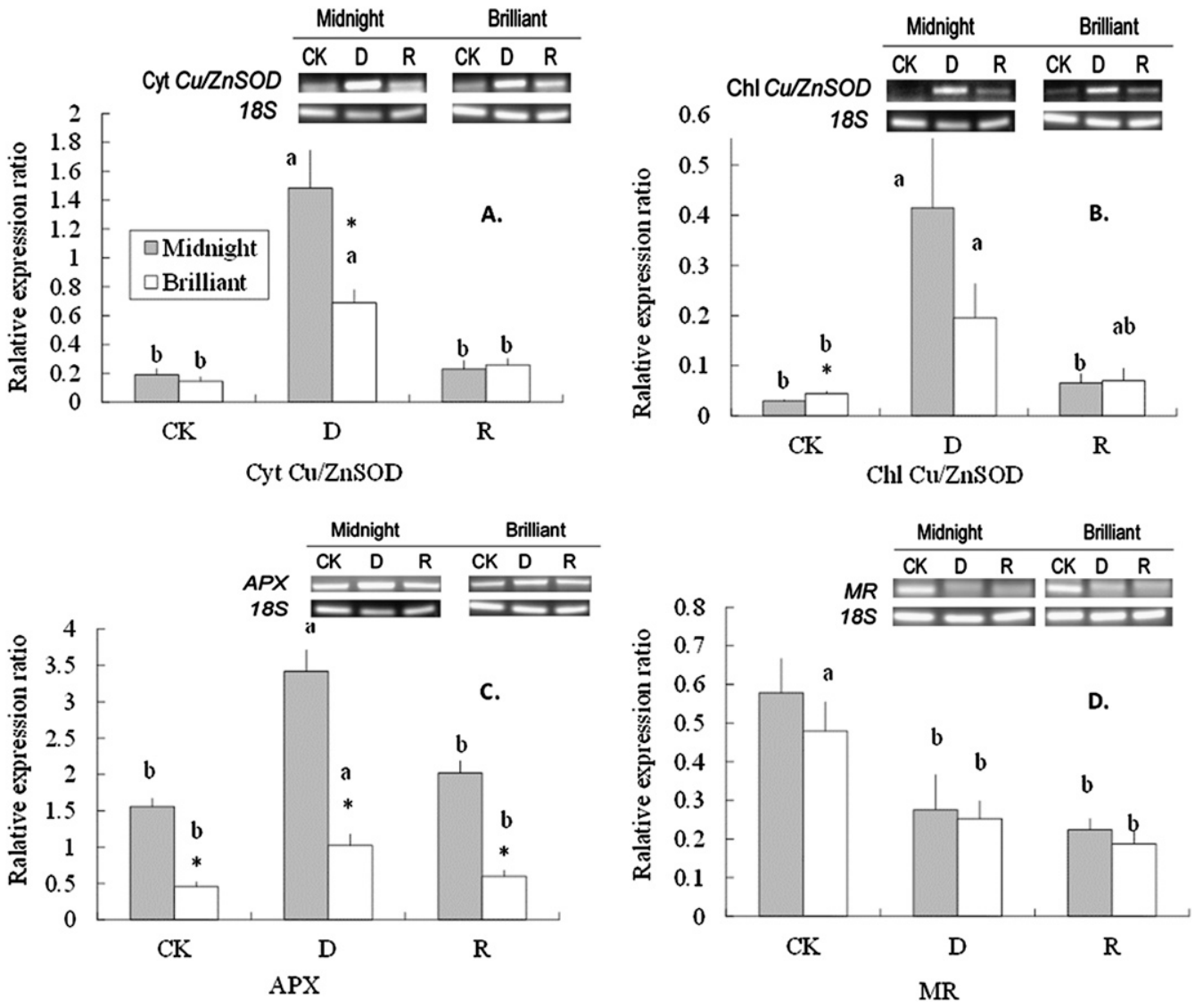

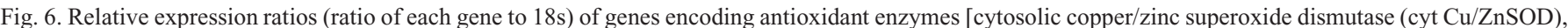
chloroplastic $\mathrm{Cu} / \mathrm{Zn}$ superoxide dismutase (chl Cu/ZnSOD), ascorbate peroxidase (APX), monodehydroascorbate reductase (MR)] under well-watered, droughtstressed ( $22 \mathrm{~d}$ for 'Midnight' and $18 \mathrm{~d}$ for 'Brilliant') and $6 \mathrm{~d}$ rewatering conditions for two kentucky bluegrass culivars, drought-tolerant 'Midnight' and droughtsensitive 'Brilliant' $(\mathrm{CK}=$ well-watered; $\mathrm{D}=$ drought; $\mathrm{R}=6 \mathrm{~d}$ rewatering). Bars indicate $\pm \mathrm{SE}(\mathrm{n}=3)$. For each cultivar, bars having the same letter indicate no significant enzyme activity difference in that particular cultivar. For each treatment, the asterisk means a significant cultivar difference exists $(P \leq 0.05)$. 
$C u / Z n S O D$ and $M R$ were detected under well-watered control, drought stress, or rewatering conditions. These data suggest that the better drought tolerance of 'Midnight' could be associated with increased expression of specific genes encoding antioxidant enzymes such as Cyt $A P X$ and Cyt $C u / Z n S O D$. It seems likely that the induction in Cyt $A P X$ expression plays an important role in removing $\mathrm{H}_{2} \mathrm{O}_{2}$ and minimizing photo-oxidative damage. An Arabidopsis thaliana gain-of-function mutant with constitutively higher $A P X 2$ expression is more drought-tolerant compared with wild-type plants and exhibited improved water use efficiency (Rossel et al., 2006). Overexpressing Cyt $\mathrm{Cu} / \mathrm{ZnSOD}$ from rice in tobacco (Nicotiana tabacum) enhances the chloroplast antioxidant system and enhances tolerance to salt, water, and osmotic stresses over the wild type (Badawi et al., 2004). Transgenic rice (indica rice 'Pusa Basmati-1') plants with a stable expression of the Cyt Cu/ZnSOD gene from the mangrove plant (Avicennia marina) also revealed better abiotic stress tolerance in comparison with untransformed control plants (Prashanth et al., 2008).

For both cultivars, the gene expression pattern of $\mathrm{Cyt} \mathrm{Cu} /$ $Z n S O D$, Chl $C u / Z n S O D, A P X$, and $M R$ did not go along with the enzyme activities changes. In addition, the expression of genes showed a compensating effect on the enzyme activities. Corresponding transcripts for Cyt $\mathrm{Cu} / \mathrm{ZnSOD}, \mathrm{Chl} \mathrm{Cu} / \mathrm{ZnSOD}$, and $A P X$ were enhanced significantly during drought, whereas the enzyme activities of SOD and APX were significantly decreased by drought stress. Moreover, drought decreased the expression level of $M R$, whereas it increased MR enzyme activity. The discrepancy between gene expression and enzyme activity seen in both cultivars during drought stress and rewatering indicates enzyme activity changes were not caused by mRNA levels but were regulated at the posttranscriptional level, which in part might be enzyme inactivation/activation or degradation/synthetic processes induced by drought.

In summary, the differential responses of the activities of antioxidant enzymes to drought stress and post-drought rewatering between drought-tolerant 'Midnight' and drought-sensitive 'Brilliant' indicated that antioxidant enzymes (APX, GR, MR, and DR) in the AsA-GSH cycle may play important protective roles for cellular survival of severe water deficit (RWC $26 \%$ to $28 \%$ ), whereas CAT, POD, and APX for $\mathrm{H}_{2} \mathrm{O}_{2}$ scavenging could be associated with postdrought recovery on rewatering in kentucky bluegrass. The maintenance of higher transcripts levels of Cyt $\mathrm{Cu} / \mathrm{ZnSOD}$ and $A P X$ in 'Midnight' versus 'Brilliant' when both cultivars were exposed to the same level of water deficit suggests that the activation of cytosolic $S O D$ and $A P X$ expression could be involved in the antioxidant protection of kentucky bluegrass during drought. At both enzymatic activity and gene transcript levels, APX was significantly higher in drought-tolerant 'Midnight' than in drought-sensitive 'Brilliant', suggesting that APX could play critical roles protecting plants from drought-induced oxidative stress and the recovery from drought damages.

\section{Literature Cited}

Alscher, R.A., N. Erturk, and L.S. Heath. 2002. Role of superoxide dismutases (SODs) in controlling oxidative stress in plants. J. Expt. Bot. 53:1331-1341.

Arora, A., R.K. Sairam, and G.C. Srivastava. 2002. Oxidative stress and antioxidative system in plants. Curr. Sci. 82:1227-1238.

Asada, K. 1992. Ascorbate peroxidase-A hydrogen peroxide-scavenging enzyme in plants. Physiol. Plant. 85:235-241.
Asada, K. 1999. The water-water cycle in chloroplasts: Scavenging of active oxygens and dissipation of excess photons. Annu. Rev. Plant Physiol. Plant Mol. Biol. 50:601-639.

Baczek-Kwinta, R., A. Adamska, K. Seidler-Lozykowska, and K. Tokarz. 2010. Does the rate of German chamomile growth and development influence the response of plants to soil drought? Biologia 65:837-842.

Badawi, G.H., Y. Yasuo, S. Emi, S. Ryozo, K. Naoyoshi, T. Kunisuke, and T. Kiyoshi. 2004. Enhanced tolerance to salt stress and water deficit by overexpressing superoxide dismutase in tobacco (Nicotiana tabacum) chloroplasts. Plant Sci. 166:919-928.

Barrs, H.D. and P.E. Weatherley. 1962. A re-examination of the relative turgidity techniques for estimating water deficits in leaves. Aust. J. Biol. Sci. 15:413-428.

Bian, S. and Y. Jiang. 2009. Reactive oxygen species, antioxidant enzyme activities and gene expression patterns in leaves and roots of kentucky bluegrass in response to drought stress and recovery. Sci. Hort. 120:264-270.

Blokhina, O., E. Virolainen, and K.V. Fagerstedt. 2003. Antioxidants, oxidative damage and oxygen deprivation stress: A review. Ann. Bot. (Lond.) 91:179-194.

Blum, A. and A. Ebercon. 1981. Cell membrane stability as a measure of drought and heat tolerance in wheat. Crop Sci. 21:43-47.

Bradford, M.M. 1976. A rapid and sensitive method for the quantitation of microgram quantities of protein utilizing the principle of protein-dye binding. Anal. Biochem. 72:248-254.

Contour-Ansel, D., M.L. Torres-Franklin, M.H.C. De Carvalho, and A. D'Arcy-Lameta. 2006. Glutathione reductase in leaves of cowpea: Cloning of two cDNAs, expression and enzymatic activity under progressive drought stress, desiccation and abscisic acid treatment. Ann. Bot. (Lond.) 98:1279-1287.

DaCosta, M. and B.R. Huang. 2007. Changes in antioxidant enzyme activities and lipid peroxidation for bentgrass species in response to drought stress. J. Amer. Soc. Hort. Sci. 132:319-326.

Dhindsa, R.S. and W. Matowe. 1981. Drought tolerance in two mosses: Correlated with enzymatic defense against lipid peroxidation. J. Expt. Bot. 32:79-91.

Foyer, C.H. 1993. Plant-resistance to oxygen. Recherche 24:270-276. Fridovich, I. 1978. The biology of oxygen radicals. Science 201:875880.

Fu, J.M. and B.R. Huang. 2001. Involvement of antioxidants and lipid peroxidation in the adaptation of two cool-season grasses to localized drought stress. Environ. Exp. Bot. 45:105-114.

Genty, B., J.M. Briantais, and G.B.V. Da Silva. 1987. Effects of drought on primary photosynthetic processes of cotton leaves. Plant Physiol. 83:360-364.

Giannopolities, C.N. and S.K. Rise. 1977. Superoxide dismutases. I. Occurrence in higher plants. Plant Physiol. 59:309-314.

Gomez, J.M., J.A. Hernandez, A. Jimenez, L.A. del Rio, and F. Sevilla. 1999. Differential response of antioxidative enzymes of chloroplasts and mitochondria to long-term $\mathrm{NaCl}$ stress of pea plants. Free Radic. Res. 31:S11-S18.

Health, R.L. and L. Packer. 1968. Photoperoxiation in isolated chloroplasts. I. Kinetics and stoichiometry of fatty acid peroxidation. Arch. Biochem. Biophys. 125:189-198.

Hoagland, D.R. and D.I. Arnon. 1950. The water-culture method for growing plants without soil. California. Agr. Expt. Sta. Circ. 347:132.

Hu, L.X., Z.L. Wang, and B. Huang. 2010. Diffusion limitations and metabolic factors associated with inhibition and recovery of photosynthesis from drought stress in a C3 perennial grass species. Physiol. Plant. 139:93-106.

Huang, B. and Z. Wang. 2005. Physiological recovery of kentucky bluegrass from drought stress. Intl. Turfgrass Soc. Res. J. 10:867873.

Jiang, Y.W. and B. Huang. 2001. Effects of calcium on antioxidant activities and water relations associated with heat tolerance in two cool-season grasses. J. Expt. Bot. 52:341-349. 
Kaiser, W.M. 1987. Effect of water deficit on photosynthetic capacity. Physiol. Plant. 71:142-149.

Luna, C.M., G.M. Pastori, S. Driscoll, K. Groten, S. Bernard, and C.H. Foyer. 2005. Drought controls on $\mathrm{H}_{2} \mathrm{O}_{2}$ accumulation, catalase (CAT) activity and CAT gene expression in wheat. J. Expt. Bot. 56:417-423.

Mead, J.F. 1976. Free radical mechanisms of lipid damage and consequences for cellular membranes, p. 51-68. In: Pryor, W.A. (ed.). Free radicals in biology. Vol. 1. Academic Press, New York, NY.

Merewitz, E., W. Meyer, S. Bonos, and B. Huang. 2010. Drought stress responses and recovery of Texas $\times$ Kentucky hybrids and kentucky bluegrass genotypes in temperate climate conditions. Agron. J. 102:258-268.

Mhamdi, A., G. Queval, S. Chaouch, S. Vanderauwera, F. Van Breusegem, and G. Noctor. 2010. Catalase function in plants: A focus on Arabidopsis mutants as stress-mimic models. J. Expt. Bot. 61:4197-4220.

Mittler, R. 2002. Oxidative stress, antioxidants and stress tolerance. Trends Plant Sci. 7:405-410.

Mittler, R. and B.A. Zilinskas. 1994. Regulation of pea cytosolic ascorbate peroxidase and other antioxidant enzymes during the progression of drought stress and following recovery from drought. Plant J. 5:397-405.

Prashanth, S.R., V. Sadhasivam, and A. Parida. 2008. Over expression of cytosolic copper/zinc superoxide dismutase from a mangrove plant Avicennia mayina in indica rice var. Pusa Basmati-1 confers abiotic stress tolerance. Transgenic Res. 17:281-291.

Rachmilevitch, S., M. DaCosta, and B. Huang. 2006. Physiological and biochemical indicators for stress tolerance, p. 321-356. In: Huang, B. (ed.). Plant-environment interactions. CRC Press, New York, NY.

Reddy, P.C.O., G. Sairanganayakulu, M. Thippeswamy, P.S. Reddy, M.K. Reddy, and C. Sudhakar. 2008. Identification of stress-induced genes from the drought tolerant semi-arid legume crop horsegram (Macrotyloma uniflorum) through analysis of subtracted expressed sequence tags. Plant Sci. 175:372-384.

Rensburg, L.V. and G.H.J. Kruger. 1994. Evaluation of components of oxidative stress metabolism for use in selection of drought tolerant cultivars of Nicotiana tabacum L. J. Plant Physiol. 143:730-737.

Rossel, J.B., P.B. Walter, L. Hendrickson, W.S. Chow, A. Poole, P.M. Mullineaux, and B.J. Pogson. 2006. A mutation affecting ascorbate peroxidase 2 gene expression reveals a link between responses to high light and drought tolerance. Plant Cell Environ. 29:269-281.

Sairam, R.K., P.S. Deshmukh, and D.C. Saxena. 1998. Role of antioxidant systems in wheat genotype tolerance to water stress. Biol. Plant. 41:387-394.

Scandalios, J.G. 1993. Oxygen stress and superoxide dismutases. Plant Physiol. 101:7-12.

Scandalios, J.G., W.F. Tong, and D.G. Roupakias. 1980. Cat3, a third gene locus coding for a tissue-specific catalase in maize: Genetics, intracellular location, and some biochemical properties. Mol. Gen. Genet. 179:33-41.
Shah, K., R.G. Kumar, S. Verma, and R.S. Dubey. 2001. Effect of cadmium on lipid peroxidation, superoxide anion generation and activities of antioxidant enzymes in growing rice seedlings. Plant Sci. 161:1135-1144.

Sharma, P. and R.S. Dubey. 2005. Modulation of nitrate reductase activity in rice seedlings under aluminium toxicity and water stress: Role of osmolytes as enzyme protectant. J. Plant Physiol. 162:854864

Shigeoka, S., T. Ishikawa, M. Tamoi, Y. Miyagawa, T. Takeda, Y. Yabuta, and K. Yoshimura. 2002. Regulation and function of ascorbate peroxidase isoenzymes. J. Expt. Bot. 53:1305-1319.

Simon, E.W. 1974. Phospholipids and plant membrane permeability. New Phytol. 73:377-420.

Smirnoff, N. 1993. Tansley review 52. The role of active oxygen in the response of plants to water-deficit and desiccation. New Phytol. 125:27-58.

Sofo, A., A.C. Tuzio, B. Dichio, and C. Xiloyannis. 2005. Influence of water deficit and rewatering on the components of the ascorbateglutathione cycle in four interspecific Prunus hybrids. Plant Sci. 169:403-412.

Srivalli, B., G. Sharma, and R. Khanna-Chopra. 2003. Antioxidative defense system in an upland rice cultivar subjected to increasing intensity of water stress followed by recovery. Physiol. Plant. 119:503-512.

Torres-Franklin, M.L., D. Contour-Ansel, Y. Zuily-Fodil, and A.T. Pham-Thi. 2008. Molecular cloning of glutathione reductase cDNAs and analysis of GR gene expression in cowpea and common bean leaves during recovery from moderate drought stress. J. Plant Physiol. 165:514-521.

Turgeon, A.J. 2008. Turfgrass management. 8th Ed. Pearson Prentice Hall, Upper Saddle River, NJ.

Turkan, I., M. Bor, F. Ozdemir, and H. Koca. 2005. Differential responses of lipid peroxidation and antioxidants in the leaves of drought-tolerant $P$. acutifolius Gray and drought-sensitive $P$. vulgaris L. subjected to polyethylene glycol mediated water stress. Plant Sci. 168:223-231.

Xu, L., L. Han, and B. Huang. 2011. Membrane fatty acid composition and saturation levels associated with leaf dehydration tolerance and post-drought rehydration in kentucky bluegrass. Crop Sci. 51:273281.

Yoshimura, K., T. Ishikawa, K. Wada, T. Takeda, Y. Kamata, T. Tada, K. Nishimura, Y. Nakano, and S. Shigeoka. 2001. Characterization of monoclonal antibodies against ascorbate peroxidase isoenzymes: Purification and epitope-mapping using immunoaffinity column chromatography. Biochim. Biophys. Acta 1526:168-174.

Zaefyzadeh, M., R.A. Quliyev, S.M. Babayeva, and M.A. Abbasov. 2009. The effect of the interaction between genotypes and drought stress on the superoxide dismutase and chlorophyll content in durum wheat landraces. Turk. J. Biol. 33:1-7.

Zhang, J. and M.B. Kirkham. 1996. Antioxidant responses to drought in sunflower and sorghum seedlings. New Phytol. 132:361-373.

Zhang, X.Z. and R.E. Schmidt. 1999. Antioxidant response to hormone-containing product in kentucky bluegrass subjected to drought. Crop Sci. 39:545-551. 